\section{Deaths from Asthma in Young People}

At the beginning of this century it was taught that acute attacks of bronchial asthma were never the cause of death. ${ }^{1}$ But in the last few years reports from Australia ${ }^{2}$ and the United Kingdom ${ }^{3}{ }^{4}$ documenting the changes in mortality from asthma, and repeated warnings against the excessive use of pressurized bronchodilator aerosols, have made the medical profession and most asthmatic patients aware that an asthmatic attack is potentially fatal. Against the high incidence of asthma the numbers of deaths are relatively few. Nevertheless, in 1965, at the height of the recent "epidemic" of deaths in England and Wales (which fortunately is now receding), asthma caused 403 deaths in patients between 5 and 34 years old. Among those aged 10-14, in whom the rise in mortality was particularly severe, asthma accounted for 1 in 18 of all deaths-almost as many as leukaemia. ${ }^{3}$

Investigation into the circumstances preceding death at that time ${ }^{5}$ provided some evidence implicating the excessive use of bronchodilator aerosols, but it was not decisive. P. M. Fraser and colleagues ${ }^{6}$ have now studied a further 52 deaths which occurred between February 1968 and January 1969 among patients aged 5 to 34 . At that time mortality from asthma was declining. Despite all the publicity about the dangers of excessive use 11 patients (out of 30 for whom reliable information was obtained) appeared to have taken excessive doses of their bronchodilators in the terminal episode. At the time of the study Fraser and his colleagues estimate that $46 \%$ of the deaths could be regarded as "epidemic" (this being the excess mortality that developed in the 1960s over the mortality occurring in 1959 and 1960), and they comment that this percentage corresponded fairly closely to their finding that $37 \%$ of patients had used aerosol bronchodilators excessively in the attack that ended their life.

This report therefore confirms the relationship between the use of aerosols and the mortality rate. ${ }^{4}$ Two main hypotheses to account for this association have been proposed. The first attributes death to a toxic effect of bronchodilator aerosols. It may be either a sudden disorder of cardiac rhythm induced by circulating sympathomimetic drugs in a heart sensitized by hypoxia ${ }^{7}$ or by the fluorinated hydrocarbons used as propellants, ${ }^{8}$ or alternatively a "rebound" bronchoconstriction may follow initial bronchodilation. ${ }^{9}$ The second hypothesis is that death is simply due to severe asthma and that the association reflects the patient's self-medication with an ineffective remedy. This is particularly apt to happen with sympathomimetic bronchodilators, since the patient often finds them very effective for moderately severe attacks and may at first be reluctant to accept they are not helping in a particular attack. Whatever the cause of the association the practical remedy is the same-better education of the patient. When these drugs are prescribed, each patient must be clearly instructed that if he fails to respond to the drug it is useless and possibly dangerous to increase the dose. Instead, he requires medical advice, which in many instances will be to start a course of treatment with corticosteroids immediately. Overdosage of bronchodilator drugs virtually implies that a severe episode has lasted for several hours, so these deaths should be preventable.

What more can be done to reduce the mortality? Perhaps the most important lesson to be drawn from these reports 5 is how difficult it is to assess the severity of an asthmatic attack. $80 \%$ of deaths were reported to be "sudden and unexpected," and over $75 \%$ occurred outside hospital. Nevertheless, necropsy showed the changes of severe asthma (overdistension of the lung and extensive mucus plugging of the bronchi) in a great majority of cases. In the acute attack there are few clinical signs of value for assessing severity. Any suggestion of cyanosis is ominous, since it implies that the arterial oxygen pressure is at best half the normal value. Tachycardia has been shown to be a serious sign, ${ }^{10}$ and it should not be too readily attributed to sympathomimetic drugs, since patients who have long used them are relatively resistant to the cardio-accelerator effects of isoprenaline, ${ }^{11}$ and tachycardia occurs only with overdose of the longer acting bronchodilator drugs. ${ }^{12}$ The intensity of wheezing is not closely related to the severity of airflow obstruction. ${ }^{13}$ If doubt remains after clinical assessment about the severity of the attack, it is best to start treatment immediately with corticosteroids (or to increase the dose if the patient is already on maintenance therapy), to give oxygen in low concentrations, and to arrange for admission to a hospital with facilities for monitoring blood gases and the severity of the airways obstruction. The reports of both F. E. Speizer and P. M. Fraser and their colleagues show that most of the patients who died had had severe symptoms on previous occasions. Patients with persistently troublesome asthma or apparent "addiction" to bronchodilators need expert assessment, which must include objective measurements of airways obstruction made with a spirometer or the Wright peak flow meter. When these measurements are made it is common to find that the functional impairment is more severe than had been suspected on clinical grounds. If the treatment of the underlying disease is then intensified, it is probable that the incidence of serious, unexpected episodes will be reduced.

\footnotetext{
1 Osler, W., The Principles and Practice of Medicine, 4th edn. Edinburgh, Pentland, 1901.

2 Gandevia, B., Medical fournal of Australia, 1968, 1, 747, 884.

3 Speizer, F. E., Doll, R., and Heaf, P., British Medical Fournal, 1968, 1, 335.

4 Inman, W. H. W., and Adelstein, A. M., Lancet, 1969, 2, 279

5 Speizer, F. E., Doll, R., Heaf, P., and Strang, L. B., British Medical Fournal, 1968, 1, 339 .

Fraser, P. M., Speizer, F. E., Waters, S. D. M., Doll, R., and Mann, N. M., British Fournal of Diseases of the Chest, 1971, 65, 71 .

7 Lockett, M. F., Lancet, 1965, 2, 104.

${ }^{8}$ Bass, M., Fournal of the American Medical Association, 1970, 212, 2075.

9 Keighley, J. F., Annals of Internal Medicine, 1966, 65, 985.

0 Rees, H. A., Millar, J. S., and Donald, K. W., Quarterly Fournal of Medicine, 1968, 37, 541 .

11 Paterson, J. W., Connolly, M. E., Davies, D. S., and Dollery, C. T., Lancet, 1968, 2, 426.

12 Kennedy, M. C. S., and Simpson, W. T., British Fournal of Diseases of the Chest, 1969, 63, 165.

13 Godfrey, S., Edwards, R. H. T., Campbell, E. J. M., and Newton-Howes, J., Thorax, 1970, 25, 285.
}

\section{Cannulation of Papilla of Vater}

In 1961 B. I. Hirschowitz ${ }^{1}$ directly viewed the interior of the duodenum with a fibreoptic gastroduodenoscope. In 1966 W. C. Watson ${ }^{2}$ visualized the papilla of Vater, and in 1968 W. S. McCune and colleagues ${ }^{3}$ cannulated the papilla and obtained retrograde pancreatograms. Nevertheless, until the latest type of Japanese fibreoptic duodenoscope was developed cannulation was not a feasible clinical procedure. Most of 